4

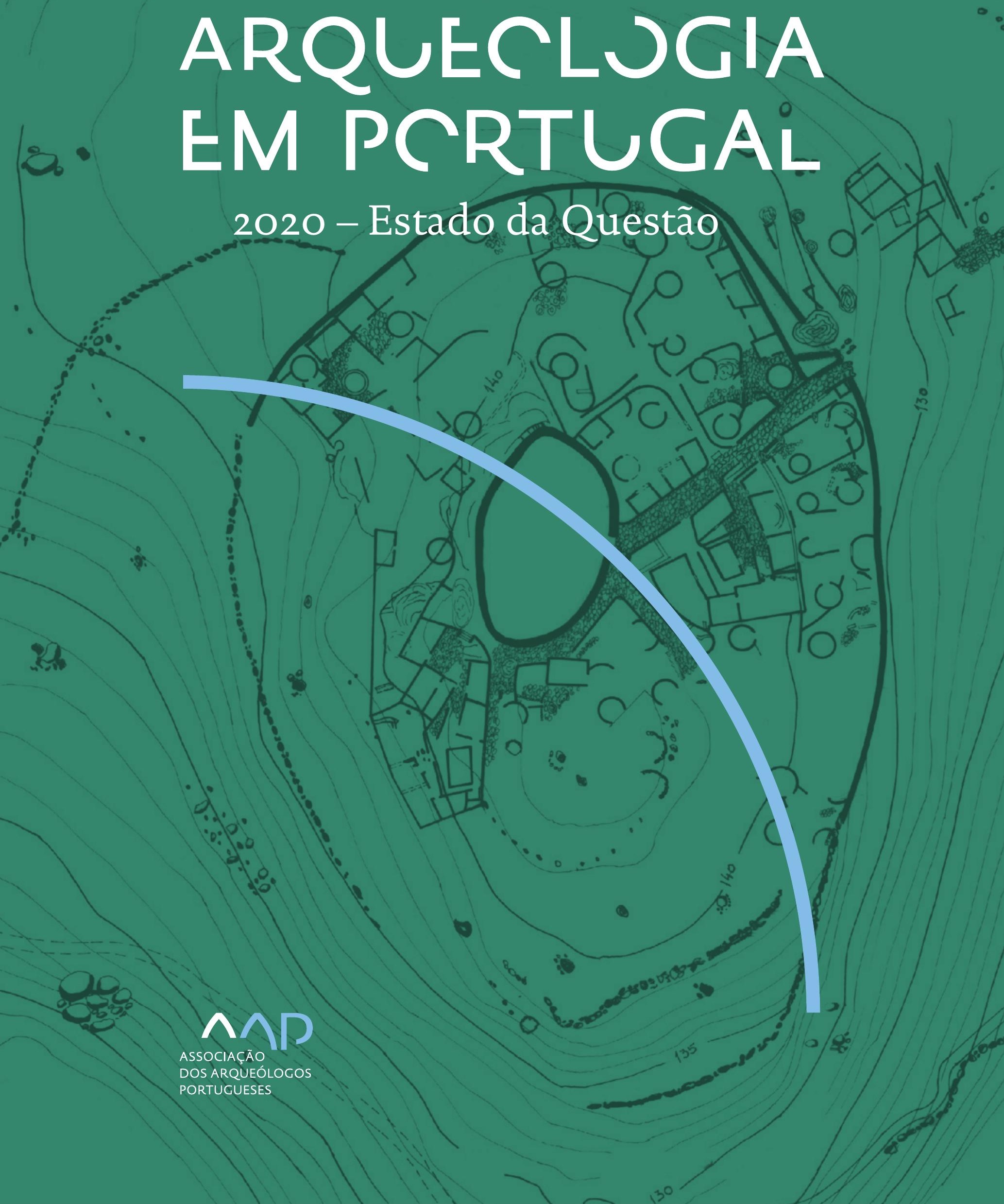


Coordenação editorial: José Morais Arnaud, César Neves e Andrea Martins Design gráfico: Flatland Design

AAP - ISBN: 978-972-9451-89-8

CITCEM - ISBN: 978-989-8970-25-1

Associação dos Arqueólogos Portugueses e CITCEM

Lisboa, 2020

O conteúdo dos artigos é da inteira responsabilidade dos autores. Sendo assim a Associação dos Arqueólogos Portugueses declina qualquer responsabilidade por eventuais equívocos ou questões de ordem ética e legal.

Desenho de capa:

Planta do castro de Monte Mozinho (Museu Municipal de Penafiel).

\section{$\hat{\wedge} \mathrm{P}$}

DOS ARQUEÓLOGOS PORTUGUESES

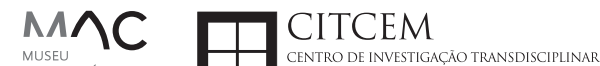
MUSEU
ARQUELLÓGICO
DO CARMO
U.PORTO

FLUP FACULDADE DE LETRAS
UNIVERSIDADE DO PORTO

Apoio

EC para a Ciência 


\section{Índice}

15 Prefácio

José Morais Arnaud

\section{Historiografia e Teoria}

17 Território, comunidade, memória e emoção: a contribuição da história da arqueologia (algumas primeiras e breves reflexões)

Ana Cristina Martins

25 Como descolonizar a arqueologia portuguesa?

Rui Gomes Coelho

41 Arqueologia e Modernidade: uma revisitação pessoal e breve de alguns aspetos da obra homónima de Julian Thomas de 2004

Vítor Oliveira Jorge

57 Dados para a História das Mulheres na Arqueologia portuguesa, dos finais do século XIX aos inícios do século XX: números, nomes e tabelas

Filipa Dimas / Mariana Diniz

73 Retractos da arqueologia portuguesa na imprensa: (in)visibilidades no feminino

Catarina Costeira / Elsa Luís

85 Arqueologia e Arqueólogos no Norte de Portugal Jacinta Bugalhão

101 Vieira Guimarães (1864-1939) e a arqueologia em Tomar: uma abordagem sobre o território e as gentes

João Amendoeira Peixoto / Ana Cristina Martins

115 Os memoráveis? A arqueologia algarvia na imprensa nacional e regional na presente centúria (2001-2019): características, visões do(s) passado(s) e a arqueologia

enquanto marca

Frederico Agosto / João Silva

129 A Evolução da Arqueologia Urbana e a Valorização Patrimonial no Barlavento Algarvio: Os casos de Portimão e Silves

Artur Mateus / Diogo Varandas / Rafael Boavida

\section{Gestão, Valorização e Salvaguarda do Património}

145 O Caderno Reivindicativo e as condições de trabalho em Arqueologia Miguel Rocha / Liliana Matias Carvalho / Regis Barbosa / Mauro Correia / Sara Simões / Jacinta Bugalhão / Sara Brito / Liliana Veríssimo Carvalho / Richard Peace / Pedro Peça / Cézer Santos

155 Os Estudos de Impacte Patrimonial como elemento para uma estratégia sustentável de minimização de impactes no âmbito de reconversões agrícolas Tiago do Pereiro

165 Salvaguarda de Património arqueológico em operações florestais: gestão e sensibilização Filipa Bragança / Gertrudes Zambujo / Sandra Lourenço / Belém Paiva / Carlos Banha / Frederico Tatá Regala / Helena Moura / Jacinta Bugalhão / João Marques / José Correia / Pedro Faria / Samuel Melro

179 Os valores do Património: uma investigação sobre os Sítios Pré-históricos de Arte Rupestre do Vale do Rio Côa e de Siega Verde José Paulo Francisco 
189 Conjugando recursos arqueológicos e naturais para potenciar as visitas ao Geoparque Litoral de Viana do Castelo (Noroeste de Portugal)

Hugo A. Sampaio / Ana M.S. Bettencourt / Susana Marinho / Ricardo Carvalhido

203 Áreas de Potencial Arqueológico na Região do Médio Tejo: Modelo Espacial Preditivo Rita Ferreira Anastácio / Ana Filipa Martins / Luiz Oosterbeek

223 Património Arqueológico e Gestão Territorial: O contributo da Arqueologia para a revisão do PDM de Avis

Ana Cristina Ribeiro

237 A coleção arqueológica do extinto Museu Municipal do Porto - Origens, Percursos e Estudos

Sónia Couto

251 Valpaços - uma nova carta arqueológica

Pedro Pereira / Maria de Fátima Casares Machado

263 Arqueologia na Cidade de Peniche

Adriano Constantino / Luís Rendeiro

273 Arqueologia Urbana: a cidade de Lagos como caso de Estudo Cátia Neto

285 Estratégias de promoção do património cultural subaquático nos Açores. O caso da ilha do Faial

José Luís Neto / José Bettencourt / Luís Borges / Pedro Parreira

297 Carta Arqueológica da Cidade Velha: Uma primeira abordagem

Jaylson Monteiro / Nireide Tavares / Sara da Veiga / Claudino Ramos / Edson Brito /

Carlos Carvalho / Francisco Moreira / Adalberto Tavares

311 Antropologia Virtual: novas metodologias para a análise morfológica e funcional Ricardo Miguel Godinho / Célia Gonçalves

\section{Didáctica da Arqueologia}

327 Como os projetos de Arqueologia podem contribuir para uma comunidade culturalmente mais consciente Alexandra Figueiredo / Claúdio Monteiro / Adolfo Silveira / Ricardo Lopes

337 Educação Patrimonial - Um cidadão esclarecido é um cidadão ativo! Ana Paula Almeida

351 A aproximação da Arqueologia à sala de aula: um caso de estudo no $3^{\circ}$ ciclo do Ensino Básico Luís Serrão Gil

363 Arqueologia 3.o - Pensar e comunicar a Arqueologia para um futuro sustentável Mónica Rolo

377 “Conversa de Arqueólogos" - Divulgar a Arqueologia em tempos de Pandemia Diogo Teixeira Dias

389 Escola Profissional de Arqueologia: desafios e oportunidades Susana Nunes / Dulcineia Pinto / Júlia Silva / Ana Mascarenhas

399 Os Museus de Arqueologia e os Jovens: a oferta educativa para o público adolescente Beatriz Correia Barata / Leonor Medeiros

411 O museu universitário como mediador entre a ciência e a sociedade: o exemplo da secção de arqueologia no Museu de História Natural e da Ciência da Universidade do Porto (MHNC-UP)

Rita Gaspar 
421 Museu de Lanifícios: Real Fábrica de Panos. Atividades no âmbito da Arqueologia Beatriz Correia Barata / Rita Salvado

427 Arqueologia Pública e o caso da localidade da Mata (Torres Novas) Cláudia Manso / Ana Rita Ferreira / Cristiana Ferreira / Vanessa Cardoso Antunes

431 Do sítio arqueológico ao museu: um percurso (também) didático Lídia Fernandes

447 Estão todos convidados para a Festa! E para dançar também... O projecto do Serviço Educativo do Museu Arqueológico do Carmo na $5^{\underline{a}}$ Edição da Festa da Arqueologia Rita Pires dos Santos

459 O “Clã de Carenque”, um projeto didático de arqueologia Eduardo Gonzalez Rocha

469 Mediação cultural: peixe que puxa carroça nas Ruínas Romanas de Troia Inês Vaz Pinto / Ana Patrícia Magalhães / Patrícia Brum / Filipa Santos

481 Didática Arqueológica, experiências do Projeto Mértola Vila Museu Maria de Fátima Palma / Clara Rodrigues / Susana Gómez / Lígia Rafael

\section{Arte Rupestre}

497 Os inventários de arte rupestre em Portugal Mila Simões de Abreu

513 O projeto FIRST-ART - conservação, documentação e gestão das primeiras manifestações de arte rupestre no Sudoeste da Península Ibérica: as grutas do Escoural e Maltravieso Sara Garcês / Hipólito Collado / José Julio García Arranz / Luiz Oosterbeek / António Carlos Silva / Pierluigi Rosina / Hugo Gomes / Anabela Borralheiro Pereira / George Nash / Esmeralda Gomes / Nelson Almeida / Carlos Carpetudo

523 Trabalhos de documentação de arte paleolítica realizados no âmbito do projeto PalæoCôa André Tomás Santos / António Fernando Barbosa / Luís Luís / Marcelo Silvestre / Thierry Aubry

537 Imagens fantasmagóricas, silhuetas elusivas: as figuras humanas na arte do Paleolítico Superior da região do Côa Mário Reis

$55^{1}$ Os motivos zoomórficos representados nas placas de tear de Vila Nova de São Pedro (Azambuja, Portugal) Andrea Martins / César Neves / José M. Arnaud / Mariana Diniz

571 Arte Rupestre do Monte de Góios (Lanhelas, Caminha). Síntese dos resultados dos trabalhos efectuados em 2007-2009 Mário Varela Gomes

599 Gravuras rupestres de barquiformes no Monte de S. Romão, Guimarães, Noroeste de Portugal Daniela Cardoso

613 Círculos segmentados gravados na Bacia do Rio Lima (Noroeste de Portugal): contributos para o seu estudo Diogo Marinho / Ana M.S. Bettencourt / Hugo Aluai Sampaio

631 Equídeos gravados no curso inferior do Rio Mouro, Monção (NW Portugal). Análise preliminar Coutinho, L.M. / Bettencourt, A.M.S / Sampaio, Hugo A.S

645 Paletas na Arte Rupestre do Noroeste de Portugal. Inventário preliminar Bruna Sousa Afonso / Ana M. S. Bettencourt / Hugo A. Sampaio 


\section{Pré-História}

661 O projeto Miño/Minho: balanço de quatro anos de trabalhos arqueológicos Sérgio Monteiro-Rodrigues / João Pedro Cunha-Ribeiro / Eduardo Méndez-Quintas / Carlos Ferreira / Pedro Xavier / José Meireles / Alberto Gomes / Manuel Santonja / Alfredo Pérez-González

677 A ocupação paleolítica da margem esquerda do Baixo Minho: a indústria lítica do sítio de Pedreiras 2 (Monção, Portugal) e a sua integração no contexto regional Carlos Ferreira / João Pedro Cunha-Ribeiro / Sérgio Monteiro-Rodrigues / Eduardo Méndez-Quintas / Pedro Xavier / José Meireles / Alberto Gomes / Manuel Santonja / Alfredo Pérez-González

693 O sítio acheulense do Plistocénico médio da Gruta da Aroeira Joan Daura / Montserrat Sanz / Filipa Rodrigues / Pedro Souto / João Zilhão

703 As sociedades neandertais no Barlavento algarvio: modelos preditivos com recurso aos SIG

Daniela Maio

715 A utilização de quartzo durante o Paleolítico Superior no território dos vales dos rios Vouga e Côa

Cristina Gameiro / Thierry Aubry / Bárbara Costa / Sérgio Gomes / Luís Luís / Carmen Manzano / André Tomás Santos

733 Uma perspetiva diacrónica da ocupação do concheiro do Cabeço da Amoreira (Muge, Portugal) a partir da tecnologia lítica Joana Belmiro / João Cascalheira / Célia Gonçalves

745 Novos dados sobre a Pré-história Antiga no concelho de Palmela. A intervenção arqueológica no sítio do Poceirão I

Michelle Teixeira Santos

757 Problemas em torno de Datas Absolutas Pré-Históricas no Norte do Alentejo Jorge de Oliveira

771 Povoamento pré-histórico nas áreas montanhosas do NO de Portugal: o Abrigo 1 de Vale de Cerdeira Pedro Xavier / José Meireles / Carlos Alves

783 Apreciação do povoamento do Neolítico Inicial na Baixa Bacia do Douro. A Lavra I (Serra da Aboboreira) como caso de estudo Maria de Jesus Sanches

797 O Processo de Neolitização na Plataforma do Mondego: os dados do Sector C do Outeiro dos Castelos de Beijós (Carregal do Sal)

João Carlos de Senna-Martinez / José Manuel Quintã Ventura / Andreia Carvalho / Cíntia Maurício

823 Novos trabalhos na Lapa da Bugalheira (Almonda, Torres Novas) Filipa Rodrigues / Pedro Souto / Artur Ferreira / Alexandre Varanda / Luís Gomes / Helena Gomes / João Zilhão

837 A pedra polida e afeiçoada do sítio do Neolítico médio da Moita do Ourives (Benavente, Portugal)

César Neves

857 Casal do Outeiro (Encarnação, Mafra): novos contributos para o conhecimento do povoamento do Neolítico final na Península de Lisboa.

Cátia Delicado / Carlos Maneira e Costa / Marta Miranda / Ana Catarina Sousa

873 Stresse infantil, morbilidade e mortalidade no sítio arqueológico do Neolítico Final/ Calcolítico ( $4^{\circ}$ e $3^{\circ}$ milénio a.C.) do Monte do Carrascal 2 (Ferreira do Alentejo, Beja) Liliana Matias de Carvalho / Sofia N. Wasterlain 
885 Come together: O Conjunto Megalítico das Motas (Monção, Viana do Castelo) e as expressões Campaniformes do Alto Minho Ana Catarina Basílio / Rui Ramos

899 Trabalhos arqueológicos no sítio Calcolítico da Pedreira do Poio Carla Magalhães / João Muralha / Mário Reis / António Batarda Fernandes

913 O sítio arqueológico de Castanheiro do Vento. Da arquitectura do sítio à arquitectura de um território João Muralha Cardoso

925 Estudo zooarqueológico das faunas do Calcolítico final de Vila Nova de São Pedro (Azambuja, Portugal): Campanhas de 2017 e 2018 Cleia Detry / Ana Catarina Francisco / Mariana Diniz / Andrea Martins / César Neves / José Morais Arnaud

943 As faunas depositadas no Museu Arqueológico do Carmo provenientes de Vila Nova de São Pedro (Azambuja): as campanhas de 1937 a 1967 Ana Catarina Francisco / Cleia Detry / César Neves / Andrea Martins / Mariana Diniz / José Morais Arnaud

959 Análise funcional de material lítico em sílex do castro de Vila Nova de S. Pedro (Azambuja, Portugal): uma primeira abordagem Rafael Lima

971 O recinto da Folha do Ouro 1 (Serpa) no contexto dos recintos de fossos calcolíticos alentejanos

António Carlos Valera / Tiago do Pereiro / Pedro Valério / António M. Monge Soares

\section{Proto-História}

987 Produção de sal marinho na Idade do Bronze do noroeste Português. Alguns dados para uma reflexão

Ana M. S. Bettencourt / Sara Luz / Nuno Oliveira / Pedro P. Simões / Maria Isabel C. Alves / Emílio Abad-Vidal

1001 A estátua-menir do Pedrão ou de São Bartolomeu do Mar (Esposende, noroeste de Portugal) no contexto arqueológico da fachada costeira de entre os rios Neiva e Cávado Ana M. S. Bettencourt / Manuel Santos-Estévez / Pedro Pimenta Simões / Luís Gonçalves

1015 O Castro do Muro (Vandoma/Baltar, Paredes) - notas para uma biografia de ocupação da Idade do Bronze à Idade Média

Maria Antónia D. Silva / Ana M. S. Bettencourt / António Manuel S. P. Silva / Natália Félix

1031 Do Bronze Final à Idade Média - continuidades e hiatos na ocupação de Povoados em Oliveira de Azeméis João Tiago Tavares / Adriaan de Man

1041 As faunas do final da Idade do Bronze no Sul de Portugal: leituras desde o Outeiro do Circo (Beja)

Nelson J. Almeida / Íris Dias / Cleia Detry / Eduardo Porfírio / Miguel Serra

1055 A Espada do Monte das Oliveiras (Serpa) - uma arma do Bronze Pleno do Sudoeste Rui M. G. Monge Soares / Pedro Valério / Mariana Nabais / António M. Monge Soares

1065 São Julião da Branca (Albergaria-a-Velha) - Investigação e valorização de um povoado do Bronze Final

António Manuel S. P. Silva / Paulo A. P. Lemos / Sara Almeida e Silva / Edite Martins de Sá

1083 Do castro de S. João ao Mosteiro de Santa Clara: notícia de uma intervenção arqueológica, em Vila do Conde Rui Pinheiro 
1095 O castro de Ovil (Espinho), um quarto de século de investigação - resultados e questões em aberto

Jorge Fernando Salvador / António Manuel S. P. Silva

1111 O Castro de Salreu (Estarreja), um povoado proto-histórico no litoral do Entre Douro e Vouga

Sara Almeida e Silva / António Manuel S. P. Silva / Paulo A. P. Lemos / Edite Martins de Sá

1127 Castro de Nossa Senhora das Necessidades (Sernancelhe): uma primeira análise artefactual Telma Susana O. Ribeiro

${ }_{1141}$ A cividade de Bagunte. O estado atual da investigação Pedro Brochado de Almeida

1153 Zoomorfos na cerâmica da Idade do Ferro no NW Peninsular: inventário, cronologias e significado Nuno Oliveira / Cristina Seoane

1163 Vasos gregos em Portugal: diferentes maneiras de contar a história do intercâmbio cultural na Idade do Ferro

Daniela Ferreira

1175 Os exotica da necrópole da Idade do Ferro do Olival do Senhor dos Mártires (Alcácer do Sal) no seu contexto regional

Francisco B. Gomes

\section{Antiguidade Clássica e Tardia}

1191 O uso de madeira como combustível no sítio da Quinta de Crestelos (Baixo Sabor): da Idade do Ferro à Romanização Filipe Vaz / João Tereso / Sérgio Simões Pereira / José Sastre / Javier Larrazabal Galarza / Susana Cosme / José António Pereira / Israel Espi

1207 Cultivos de Época Romana no Baixo Sabor: continuidade em tempos de mudança? João Pedro Tereso / Sérgio Simões Pereira / Filipe Santos / Luís Seabra / Filipe Vaz

1221 A casa romana na Hispânia: aplicação dos modelos itálicos nas províncias ibéricas Fernanda Magalhães / Diego Machado / Manuela Martins

1235 As pinturas murais romanas da Rua General Sousa Machado, n. ${ }^{5}$ 1, Chaves José Carvalho

1243 Trás do Castelo (Vale de Mir, Pegarinhos, Alijó) - Uma exploração agrícola romana do Douro

Tony Silvino / Pedro Pereira

1255 A sequência de ocupação no quadrante sudeste de Bracara Augusta: as transformações de uma unidade doméstica Lara Fernandes / Manuela Martins

1263 Os Mosaicos com decoração geométrica e geométrico-vegetalista dos sítios arqueológicos da área do Conuentus Bracaraugustanus. Novas abordagens quanto à conservação, restauro, decoração e datação Maria de Fátima Abraços / Licínia Wrench

1277 “Casa Romana” do Castro de São Domingos (Cristelos, Lousada): Escavação, Estudo e Musealização Paulo André de P. Lemos

1291 A arqueobotânica no Castro de Guifões (Matosinhos, Noroeste de Portugal): O primeiro estudo carpológico

Luís Seabra / Andreia Arezes / Catarina Magalhães / José Varela / João Pedro Tereso 
1305 Um Horreum Augustano na Foz do Douro (Monte do Castelo de Gaia, Vila Nova de Gaia) Rui Ramos

1311 Ponderais romanos na Lusitânia: padrões, formas, materiais e contextos de utilização Diego Barrios Rodríguez

1323 Um almofariz centro-itálico na foz do Mondego

Marco Penajoia

1335 Estruturas romanas de Carnide - Lisboa Luísa Batalha / Mário Monteiro / Guilherme Cardoso

1347 O contexto funerário do sector da "necrópole NO" da Rua das Portas de S. Antão (Lisboa): o espaço, os artefactos, os indivíduos e a sua interconectividade na interpretação do passado Sílvia Loja, José Carlos Quaresma, Nelson Cabaço, Marina Lourenço, Sílvia Casimiro, Rodrigo Banha da Silva, Francisca Alves-Cardoso

${ }_{1361}$ Povoamento em época Romana na Amadora - resultados de um projeto pluridisciplinar Gisela Encarnação / Vanessa Dias

1371 A Arquitectura Residencial em Mirobriga (Santiago do Cacém): contributo a partir de um estudo de caso Filipe Sousa / Catarina Felício

${ }_{1385}$ O fim do ciclo. Saneamento e gestão de resíduos nos edifícios termais de Mirobriga (Santiago do Cacém)

Catarina Felício / Filipe Sousa

1399 Balsa, Topografia e Urbanismo de uma Cidade Portuária Vítor Silva Dias / João Pedro Bernardes / Celso Candeias / Cristina Tété Garcia

1413 No Largo das Mouras Velhas em Faro (2017): novas evidências da necrópole norte de Ossonoba e da sua ocupação medieval Ricardo Costeira da Silva / Paulo Botelho / Fernando Santos / Liliana Nunes

1429 Instrumentos de pesca recuperados numa fábrica de salga em Ossonoba (Faro) Inês Rasteiro / Ricardo Costeira da Silva / Paulo Botelho

1439 A Necrópole Romana do Eirô, Duas Igrejas (Penafiel): intervenção arqueológica de 2016 Laura Sousa / Teresa Soeiro

1457 Ritual, descarte ou afetividade? A presença de Canis lupus familiaris na Necrópole Noroeste de Olisipo (Lisboa)

Beatriz Calapez Santos / Sofia Simões Pereira / Rodrigo Banha da Silva / Sílvia Casimiro / Cleia Detry / Francisca Alves Cardoso

1467 Dinâmicas económicas em Bracara na Antiguidade Tardia Diego Machado / Manuela Martins / Fernanda Magalhães / Natália Botica

1479 Cerâmicas e Vidros da Antiguidade Tardia do Edifício sob a Igreja do Bom Jesus (Vila Nova de Gaia) Joaquim Filipe Ramos

1493 Novos contributos para a topografia histórica de Mértola no período romano e na Antiguidade Tardia Virgílio Lopes

\section{8. Época Medieval}

1511 Cerâmicas islâmicas no Garb setentrional "português": algumas evidências e incógnitas Constança dos Santos / Helena Catarino / Susana Gómez / Maria José Gonçalves / Isabel Inácio / Gonçalo Lopes / Jacinta Bugalhão / Sandra Cavaco / Jaquelina Covaneiro / Isabel Cristina Fernandes / Ana Sofia Gomes 
1525 Contributo para o conhecimento da cosmética islâmica, em Silves, durante a Idade Média Rosa Varela Gomes

1537 Yábura e o seu território - uma análise histórico-arqueológica de Évora entre os séculos VIII-XII José Rui Santos

1547 A encosta sul do Castelo de Palmela - resultados preliminares da escavação arqueológica Luís Filipe Pereira / Michelle Teixeira Santos

1559 A igreja de São Lourenço (Mouraria, Lisboa): um conjunto de silos e de cerâmica medieval islâmica

Andreia Filipa Moreira Rodrigues

1571 O registo material de movimentações populacionais no Médio Tejo, durante os séculos XII-XIII. Dois casos de "sunken featured buildings", nos concelhos de Cartaxo e Torres Novas Marco Liberato / Helena Santos / Nuno Santos

1585 O nordeste transmontano nos alvores da Idade média. Notas para reflexão Ana Maria da Costa Oliveira

1601 Sepulturas escavadas na rocha do Norte de Portugal e do Vale do Douro: primeiros resultados do Projecto SER-NPVD

Mário Jorge Barroca / César Guedes / Andreia Arezes / Ana Maria Oliveira

1619 "Portucalem Castrum Novum" entre o Mediterrâneo e o Atlântico: o estudo dos materiais cerâmicos alto-medievais do arqueossítio da rua de D. Hugo, nํ. 5 (Porto) João Luís Veloso

1627 A Alta Idade Média na fronteira de Lafões: notas preliminares sobre a Arqueologia no Concelho de Vouzela

Manuel Luís Real / Catarina Tente

1641 Um conjunto cerâmico medieval fora de portas: um breve testemunho aveirense Susana Temudo

${ }_{1651}$ Os Lóios do Porto: uma perspetiva integrada no panorama funerário da Baixa Idade Média à Época Moderna em meios urbanos em Portugal

Ana Lema Seabra

1659 O Caminho Português Interior de Santiago como eixo viário na Idade Média Pedro Azevedo

1665 Morfologia Urbana: Um exercício em torno do Castelo de Ourém André Donas-Botto / Jaqueline Pereira

1677 Intervenção arqueológica na Rua Marquês de Pombal/Largo do Espírito Santo (Bucelas, Loures)

Florbela Estêvão / Nathalie Antunes-Ferreira / Dário Ramos Neves / Inês Lisboa

1691 O Cemitério Medieval do Poço do Borratém e a espacialidade funerária na cidade de Lisboa Inês Belém / Vanessa Filipe / Vasco Noronha Vieira / Sónia Ferro / Rodrigo Banha da Silva

1705 Um Espaço Funerário Conventual do séc. XV em Lisboa: o caso do Convento de São Domingos da Cidade Sérgio Pedroso / Sílvia Casimiro / Rodrigo Banha da Silva / Francisca Alves Cardoso

\section{9. Época Moderna e Contemporânea}

1721 Arqueologia Moderna em Portugal: algumas reflexões críticas em torno da quantificação de conjuntos cerâmicos e suas inferências históricas e antropológicas Rodrigo Banha da Silva / André Bargão / Sara da Cruz Ferreira

1733 Faianças de dois contextos entre os finais do século XVI e XVIII do Palácio dos Condes de Penafiel, Lisboa

Martim Lopes / Tomás Mesquita 
1747 Um perfil de consumo do século XVIII na foz do Tejo: O caso do Mercado da Ribeira, Lisboa Sara da Cruz Ferreira / Rodrigo Banha da Silva / André Bargão

1761 Os Cachimbos dos Séculos XVII e XVIII do Palácio Mesquitela e Convento dos Inglesinhos (Lisboa)

Inês Simão / Marina Pinto / João Pimenta / Sara da Cruz Ferreira / André Bargão / Rodrigo Banha da Silva

1775 "Tomar os fumos da erua que chamão em Portugal erua sancta». Estudo de Cachimbos provenientes da Rua do Terreiro do Trigo, Lisboa

Miguel Martins de Sousa / José Pedro Henriques / Vanessa Galiza Filipe

1787 Cachimbos de Barro Caulínitico da Sé da Cidade Velha (República de Cabo Verde)

Rodrigo Banha da Silva / João Pimenta / Clementino Amaro

1801 Algumas considerações sobre espólio não cerâmico recuperado no Largo de Jesus (Lisboa) Carlos Boavida

1815 Adereços de vidro, dos séculos XVI-XVIII, procedentes do antigo Convento de Santana de Lisboa (anéis, braceletes e contas)

Joana Gonçalves / Rosa Varela Gomes / Mário Varela Gomes

1837 Da ostentação, luxo e poder à simplicidade do uso quotidiano: arqueologia e simbologia de joias e adornos da Idade Moderna Portuguesa Jéssica Iglésias

1849 Os amuletos em Portugal - dos objetos às superstições: o coral vermelho Alexandra Vieira

1865 Cerâmicas de Vila Franca de Xira nos séculos XV e XVI Eva Pires

1879 «Não passa por teu o que me pertence». Marcas de individualização associadas a faianças do Convento de Nossa Senhora de Aracoeli, Alcácer do Sal Catarina Parreira / Íris Fragoso / Miguel Martins de Sousa

1891 Cerâmica de Leiria: alguns focos de produção

Jaqueline Pereira / André Donas-Botto

1901 Os Fornos na Rua da Biquinha, em Óbidos Hugo Silva / Filipe Oliveira

1909 A casa de Pêro Fernandes, contador dos contos de D. Manuel I: o sítio arqueológico da Silha do Alferes, Seixal (século XVI) Mariana Nunes Ferreira

1921 O Alto da Vigia (Sintra) e a vigilância e defesa da costa Alexandre Gonçalves / Sandra Santos

1937 O contexto da torre sineira da Igreja de Santa Maria de Loures Paulo Calaveira / Martim Lopes

1949 A Necrópole do Hospital Militar do Castelo de São Jorge e as práticas funerárias na Lisboa de Época Moderna Susana Henriques / Liliana Matias de Carvalho / Ana Amarante / Sofia N. Wasterlain

1963 SAND - Sarilhos Grandes Entre dois Mundos: o adro da Igreja e a Paleobiologia dos ossos humanos recuperados

Paula Alves Pereira / Roger Lee Jesus / Bruno M. Magalhães

1975 Expansão urbana da vila de Cascais no século XVII e XVIII: a intervenção arqueológica na Rua da Vitória no 15 a 17

Tiago Pereira / Vanessa Filipe

1987 Novos dados para o conhecimento do Urbanismo de Faro em época Moderna Ana Rosa 
1995 Um exemplo de Arqueologia Urbana em Alcoutim: o Antigo Edifício dos CTT Marco Fernandes / Marta Dias / Alexandra Gradim / Virgílio Lopes / Susana Gómez Martínez

2007 Palácio dos Ferrazes (Rua das Flores/Rua da Vitória, Porto): a cocheira de Domingos Oliveira Maia

Francisco Raimundo

2021 As muitas vidas de um edifício urbano: História, Arqueologia e Antropologia no antigo Recreatório Paroquial de Penafiel Helena Bernardo / Jorge Sampaio / Marta Borges

2035 O convento de Nossa Senhora da Esperança de Ponta Delgada: o contributo da arqueologia para o conhecimento de um monumento identitário João Gonçalves Araújo / N’Zinga Oliveira

2047 Arqueologia na ilha do Corvo... em busca da capela de Nossa Senhora do Rosário Tânia Manuel Casimiro / José Luís Neto / Luís Borges / Pedro Parreira

2059 Perdidos à vista da Costa. Trabalhos arqueológicos subaquáticos na Barra do Tejo Jorge Freire / José Bettencourt / Augusto Salgado

2071 Arqueologia marítima em Cabo Verde: enquadramento e primeiros resultados do projecto CONCHA

José Bettencourt / Adilson Dias / Carlos Lima / Christelle Chouzenoux / Cristóvão Fonseca / Dúnia Pereira / Gonçalo Lopes / Inês Coelho / Jaylson Monteiro / José Lima / Maria Eugénia Alves / Patrícia Carvalho / Tiago Silva

2085 Trabalhos arqueológicos na Cidade Velha (Ribeira Grande de Santiago, Cabo Verde): reflexões sobre um projecto de investigação e divulgação patrimonial André Teixeira / Jaylson Monteiro / Mariana Mateus / Nireide Tavares / Cristovão Fonseca / Gonçalo C. Lopes / Joana Bento Torres / Dúnia Pereira / André Bargão / Aurélie Mayer / Bruno Zélie / Carlos Lima / Christelle Chouzenoux / Inês Henriques / Inês Pinto Coelho / José Lima / Patrícia Carvalho / Tiago Silva

2103 A antiga fortificação de Quelba / Khor Kalba (E.A.U.). Resultados de quatro campanhas de escavações, problemáticas e perspectivas futuras Rui Carita / Rosa Varela Gomes / Mário Varela Gomes / Kamyar Kamyad

2123 Colónias para homens novos: arqueologia da colonização agrária fascista no noroeste ibérico Xurxo Ayán Vila / José Mạ . Señorán Martín 


\title{
AS SOCIEDADES NEANDERTAIS NO BARLAVENTO ALGARVIO: MODELOS PREDITIVOS COM RECURSO AOS SIG
}

\author{
Daniela Maio ${ }^{1}$
}

\begin{abstract}
RESUMO
Os estudos relacionados com as populações de Neandertais no Barlavento algarvio indicam que os territórios ocupados se localizavam no litoral, onde a recolha de recursos aquáticos e a caça de animais de pequeno e grande porte fazia parte da dieta destas comunidades. De forma a contribuir com novos dados para o Paleolítico Médio foi criado um Modelo Preditivo Arqueológico com o intuito de analisar os padrões de ocupação e exploração do território. O presente estudo assenta numa abordagem essencialmente estatística, descritiva e univariada, com recurso a variáveis dependentes (i.e., sítios arqueológicos) e independentes (e.g., dados geomorfológicos, geográficos). Os resultados obtidos indicam uma ocupação do território pouco dispersa, junto da costa e ligada a importantes vales e rios.

Palavras-chave: Modelo Preditivo Arqueológico, Sistemas de Informação Geográfica, Paleolítico Médio, Barlavento Algarvio.
\end{abstract}

\begin{abstract}
Studies related to Neanderthal populations in the western Algarve indicate that the occupied territories were located near the coastline, where the collection of aquatic resources and the hunting of small and large animals was part of the diet of these communities. To contribute with new data for the Middle Paleolithic, an Archaeological Predictive Model was created to analyze the patterns of occupation and exploration of the territory. The present study is based on an essentially statistical, descriptive and univariate approach, using dependent variables (i.e., archaeological sites) and independent variables (e.g., geomorphological, geographic data). The results obtained indicate an occupation of the territory, close to the coastline and dispersed in the territory, linked to important valleys and rivers.

Keywords: Archaeological Predictive Model, Geographic Information Systems, Middle Paleolithic, Eastern Algarve.
\end{abstract}

\section{INTRODUÇÃO}

Os Neandertais seriam uma outra espécie ou uma variedade do Homo sapiens? Esta tem sido uma das questões mais debatidas por vários investigadores, que ao longo do tempo têm vindo a caracterizar o comportamento do H. Neandertal (e.g., Raposo, 1995; Stringer, 2002; Bicho, 2005; Zilhão, 2014). A investigação sobre o Paleolítico Médio tem fornecido novas informações integrando todo um conjunto de estudos que vão desde análises líticas (e.g., Veríssimo, 2004; Mendonça, 2009; Pereira, Haws \&
Bicho, 2012; Pereira \& Benedetti, 2013; Paixão \& alii, 2016; Bicho \& Cascalheira, 2018), análises isotópicas e genéticas (e.g., Fabre \& alii, 2011; Bocherens, Drucker \& Madelaine, 2014; Wißing \& alii, 2019) até à reconstrução das dietas alimentares (Bicho, 2004a, 2004b; Bicho, Cascalheira \& Marreiros, 2012) e padrões de povoamento e/ou exploração do território (d'Errico \& Sánchez Goñi, 2003; Bradtmöller \& alii, 2012; Maio, 2018). Afastando a hipótese de que os Neandertais seriam uma espécie primitiva, e sim incluídos no género Homo (Stringer, 2002). O sul de Portugal possui uma alta diversidade lito-

1. Interdisciplinary Center for Archaeology and Evolution of Human Behavior - ICArEHB, FCHS, Campus de Gambelas, University of Algarve, Faro 8005-139, Portugal; daniela.s.maio@hotmail.com 
lógica, o que se reflete na riqueza da sua geomorfologia (Dias, 1998), constituindo um ponto atrativo para as comunidades do Pleistocénico Final. As pesquisas sobre o Paleolítico Médio na região foram pontuais. No entanto, desde o final do século XX, a situação foi revertida e vários projetos surgiram para a região a oeste do Algarve, como por exemplo o projeto "A Ocupação Humana Paleolítica no Algarve" (Bicho, 2004a, 2004b). Deste projeto resultou a identificação de um conjunto de dez sítios arqueológicos, divido em dois grupos: (1) o primeiro caracterizado pela proximidade a zonas costeiras e de estuários - Ibn Ammar, Praia da Galé e Vale da Fonte; (2) e, um outro grupo marcado pela proximidade a lagos - Lagoa Funda 1, 2 e 3 e Lagoa do Bordoal. Os dados provenientes dos sítios arqueológicos indicam a preferência por uma posição costeira, onde a recolha de recursos aquáticos e a caça de animais de pequeno e grande porte integravam a dieta do Homo Neandertal (Bicho, 2004a, 2004b).

No entanto, as lacunas na investigação do Paleolítico Médio nesta região ainda persistem, refletindo-se nos (1) modelos de povoamento estabelecidos (apenas teóricos) e, (2) na fragmentação dos dados, que comprometem a compreensão da interação destas comunidades com o território. De modo a contribuir com novos dados para as várias questões que ainda se encontram por responder: De que forma os Neandertais exploravam e ocupavam o território? Onde se localizam os sítios arqueológicos do Paleolítico Médio? De que forma o ambiente influenciou as estratégias do uso do território? desenvolveu-se um modelo preditivo arqueológico recorrendo aos dados arqueológicos existentes. Assim, este artigo pretende mostrar os resultados preliminares obtidos através da criação do Modelo Preditivo Arqueológico (MPA) para o Paleolítico Médio no Barlavento algarvio, que resultou na dissertação de mestrado da autora. O objetivo principal é identificar padrões de ocupação e exploração do território e estabelecer novos paradigmas na relação homem-ambiente. Concretamente, pretende-se: (1) identificar áreas de maior potencial arqueológico; (2) verificar a eficácia do modelo preditivo na área da costa algarvia; (3) definir a importância que os recursos têm para as sociedades do Paleolítico Médio; e (4) estabelecer novos dados sobre a interação das comunidades com o meio ambiente (e.g., proximidade a cursos de água). O recurso aos Sistemas de Informação Geográfica (SIG) para a criação do MPA, só é possível devido ao avanço tecnológico verificado na década de 1950 e 1960, quando surgiram os primeiros conceitos e métodos na geografia quantitativa. A criação de MPA tem vindo a aumentar devido às suas potencialidades analíticas e capacidades gráficas inerentes aos SIG (Gonçalves, 2009). A metodologia adotada para a criação do MPA e seleção das variáveis dependentes (i.e., sítios arqueológicos) e independentes (e.g., litologia, altitude, declive, índice de posição topográfica, cursos de água, distância ao litoral) a incluir no modelo passou por uma abordagem estatística, descritiva e univariada. Numa primeira fase, foi coletada a cartografia da região, através das Cartas Militares de Portugal o que permitiu a criação do Modelo Digital do Terreno (MDT) e o respetivo mapeamento temático (e.g., mapas de declives, orientação de declives, radiação e exposição solar). Após a obtenção das variáveis, foram realizados testes estatísticos, como análise da variabilidade interna dos dados, com o objetivo de identificar as variáveis independentes que continham informações redundantes. Esta metodologia é justificável uma vez que pretende compreender a distribuição do povoamento durante este período, assim como prever a localização de novos sítios arqueológicos com as mesmas características.

\section{MODELOS PREDITIVOS ARQUEOLÓGICOS}

\subsection{Sistemas de Informação Geográfica}

Os SIG surgiram de forma isolada em várias empresas privadas e organismos administrativos estatais durante a década de 1970, onde o principal objetivo seria combinar diferentes dados no mesmo mapa (Nazareno, 2005). Estes podem ser descritos, genericamente, como uma ferramenta que é "aplicada direta ou indiretamente, nas mais variadas tarefas como por exemplo, modelação socioeconómica e ambiental, coordenação de projetos, padronização de dados ...” (Gonçalves, 2014, pp.107). Não obstante, o conceito mais comum encontra-se associado à produção e análise de cartografia através da tecnologia computacional, com um sistema de hardware e software que permite armazenar, manipular, recolher, guardar, pesquisar, transformar e visualizar informação georreferenciada num ambiente orientado para resolução de problemas (Cowen, 1988; Gonçalves, 2014). No sentido prático, caracteriza-se por ser um programa informático utilizado para o tratamento de dados, sendo que a informação real é discriminada através de layers (camadas informativas) de uma 
determinada área de estudo, que podem ser apresentados entre si ou isoladamente (Gonçalves, 2009).

A sua crescente utilização deve-se a fatores relacionados, em parte, com a redução do preço do hardware e software, facilidade de comunicação ao nível da visualização, gestão e evolução dos dados digitais georreferenciados, como GPS (Global Position System), e gestão geográfica do espaço (ESRI Portugal, 2020). A partir de 1990 é evidente um aumento da utilização desta ferramenta por parte dos arqueólogos, e desde então tem evoluído significativamente, principalmente em termos da informação geográfica, de análise e representação visual dos dados. Esta ferramenta multifuncional veio revolucionar a investigação arqueológica uma vez que pretende responder a questões de índole espacial, por meio da representação tridimensional do mundo onde podem ser testados padrões, hipóteses e construir Modelos Preditivos Arqueológicos (e.g., Gonçalves, 2014; Maio, 2018; Verhagen, 2018).

\subsection{Modelos Preditivos Arqueológicos}

Os MPA caracterizam-se por serem mapas que apresentam as áreas de maior e menor potencialidade arqueológico de acordo com os critérios pré-selecionados e que podem ser explicados por padrões (Project Development, 2005; Gonçalves, 2014). A construção destes modelos é realizada com recurso à análise geoestatística, através de proxys naturais (e.g., rede hidrográfica, altitude, orientação das encostas) e padrões arqueológicos. No entanto, os MPA têm sido alvo de controvérsia, tanto a nível teórico como a nível metodológico (e.g., Judge \& Sebastian, 1988; Kvamme, 1990; Kohler \& Parker, 1986; Warren \& Asch, 200o). Segundo Gonçalves (2014) as críticas podem ser agrupadas em quatro categorias:

1. Arqueológica - relacionada com o facto de muitos sítios ainda estarem por descobrir e, outros pobremente referenciados;

2. Ambiental - a paisagem atual difere da paisagem do passado, apenas utilizadas como proxis das variáveis que realmente marcaram as sociedades do passado;

3. Comportamental - a natureza do comportamento humano é muito distinta no tempo e no espaço, em que os ambientes socioculturais tornam-se impossíveis de modelar;

4. Técnicas - os dados cartográficos não têm a capacidade suficiente para representar fielmente o mundo real.
De forma a minimizar o erro, as variáveis independentes a serem usadas devem ser as que se mantiveram relativamente estáveis ao longo do tempo, como por exemplo o Índice de Posição Topográfica. A utilização de dados atuais apresenta vantagens pelo facto de o erro ser quantificável. Deve ser realçado o facto de que os modelos preditivos criam uma abordagem complementar e independente aos estudos da cultura material, na tentativa de codificar aspetos do comportamento humano, embora este não possa ser completamente reconstruído. Para criar um MPA é necessário realizar determinados passos, e, segundo vários autores este processo pode ser dividido em três fases: (1) recolha e organização dos dados; (2) desenvolvimento do modelo e testes; e (3) refinação e aperfeiçoamento (Carr, 1985; Warren, 1990).

Partindo da análise das características de implantação de um dado conjunto de sítios arqueológicos de uma mesma região, procura-se estabelecer padrões, de forma a compreender o peso que as que características ambientais tiveram no momento da escolha do sítio, sendo possível definir, de forma genérica, uma função que traduz essa relação:

$$
y=f\left(x 1, x 2, x 3, \ldots, x_{n}\right)
$$

Deste modo, $y$ representa a localização dos sítios arqueológicos e $x$ as características que condicionam a localização; consequentemente diz-se que a primeira é uma variável dependente, enquanto as últimas se denominam de variáveis independentes. Estas variáveis são essenciais no momento de avaliar os critérios que se registam numa determinada distribuição espacial, encontrando-se a sua escolha dependente das questões colocadas (Gonçalves, 2014).

\section{METODOLOGIA}

\subsection{Sítios arqueológicos e área de estudo}

Para esta análise foram selecionados um total de dez sítios arqueológicos, com níveis arqueológicos atribuíveis ao Paleolítico Médio. Estes, resultaram do projeto supracitado (com a exceção da gruta da Companheira) no âmbito da realização de trabalhos de emergência e intervenção arqueológica na região (Bicho, 2004a). O conjunto de sítios é composto por oito sítios de ar livre, nomeadamente, Praia da Galé, Curva do Belixe, Vale Santo 3, Lagoa Funda 1, Lagoa Funda 2, Lagoa Funda 3, Lagoa do Bordoal e Vale da Fonte e duas grutas, Ibn Ammar (Bicho, 2004b) e 
Companheira $^{2}$ (informação pessoal, Nuno Bicho) (Figura 1A, 1C, 1D).

$\mathrm{Na}$ sua maioria, o conjunto de sítios localiza-se no concelho de Vila do Bispo, com exceção dos sítios arqueológicos da Praia da Galé (Albufeira), gruta de Ibn Ammar (Lagoa) e gruta da Companheira (Portimão). Regra geral, os sítios de ar livre encontram-se distribuídos em áreas que apresentam uma altitude entre os $10 \mathrm{~m}$ e os $130 \mathrm{~m}$. Estes revelaram exclusivamente materiais líticos em quartzo, quartzito e sílex, sendo que apresentavam uma morfologia muito semelhante entre si (e.g., denticulados, raspadores e núcleos) (Mendonça, 2009; Bicho, 2004a, 2004b). Por sua vez, as grutas de Ibn Ammar e da Companheira localizam-se perifericamente junto das margens do rio Arade, nas arribas calcárias do Jurássico a uma altitude de c.1o $\mathrm{m}$, onde detinham uma boa visibilidade sobre o terreno adjacente assim como, um acesso facilitado ao rio. As margens do rio Arade, compostas por extensas zonas de sapal, seriam, durante o Paleolítico Médio um verdadeiro nicho ecológico. Ambas as grutas apresentaram no seu registo arqueológicos utensílios líticos atribuíveis ao Moustierense (e.g., lascas Levallois e discoide), tal como uma variedade de restos faunísticos (e.g., ossos de colho, auroque, veado) e moluscos marinhos (Bicho, 2004a, 2004b) (Tabela 1). A área de análise corresponde ao barlavento algarvio, situado no extremo sul de Portugal continental, a oeste da Península Ibérica. A zona litoral apresenta uma diversidade elevada no que diz respeito à geologia, na qual as formações vão sendo mais recentes do cabo de S. Vicente para leste (Jurássico até ao Quaternário) (Dias, 1988). A região em estudo enquadra-se na Bacia Meso-cenozoica ou Bacia Algarvia, com uma alegada extensão de $150 \mathrm{~km}$ e 30 $\mathrm{km}$ de largura, com orientação este-oeste (Moura e Boski, 1999). Atendendo às características paisagísticas e à sua diversidade a região pode ser dividida geomorfologicamente em três sub-regiões: (1) Serra (Paleozoica); (2) Barrocal (Mesozoico); e (3) Litoral (Mesocenozoico) (Figura 1B).

Por norma, os sítios arqueológicos localizam-se na zona do litoral, caracterizado por costas abruptas, lagunas recortadas, sapais, formações dunares e relevos aplanares. Esta diversidade permitiu diferenciar a zona litoral pela Costa Vicentina, litoral de arribas e

2. A gruta da Companheira foi descoberta somente em 2016 aquando da construção de uma ETAR, nas margens do rio Arade, concelho de Portimão (informação pessoal, Nuno Bicho). areal arenoso (Dias, 1988). A seleção da área de análise teve em consideração critérios relacionados com o espaço geográfico ocupado e/ou explorado pelas comunidades humanas do Paleolítico Médio, tal como critérios geológicos, geomorfológicos e hidrológicos.

\subsection{Mapeamento e análises em ambiente SIG}

A criação dos modelos implicou uma recolha aprofundada de um conjunto de dados, destacando-se, pela sua relevância, a cartografia da região do barlavento algarvio. As fontes utilizadas para a sua obtenção foram as seguintes: Direção-Geral do Território (Carta Administrativa Oficial Portuguesa, que fornece os limites administrativos de Portugal Continental), Sistema Nacional de Informação de Ambiente (Carta Litológica e Carta Batimétrica à escala 1:1 ooo ooo), Instituto Geográfico do Exército (Cartas Militares Portuguesas à escala 1:25 00o). As Cartas Militares Portuguesas forneceram a base topográfica (e.g., isolinhas, pontos de máximos e mínimos) para a criação do Modelo Digital do Terreno (MDT) (Figura 2).

Após a obtenção da cartografia procedeu-se à georreferenciação das Cartas Militares, e de seguida à vectorização de alguns dos seus elementos, nomeadamente, linha da costa, curvas de nível e cursos de água, e à edição, na tabela de atributos, dos respetivos dados (e.g., cursos de água - ordem e designação; curvas de nível - valor da altitude de cada curva).

O passo seguinte consistiu na criação do MDT, essencial para a criação de modelos preditivos, uma vez que permite representar não só as características do terreno (e.g., altimetria), como também, a criação de cartografia temática derivada (e.g., mapas de declive, orientação do declive, radiação e exposição solar, etc). Desta forma, os mapas que integram a criação do MPA foram: Altitude, Declive, Orientação do Declive e Índice de Posição Topográfica. Para se proceder à análise estatística foram selecionadas as variáveis dependentes, da qual a criação do MPA depende (conjunto de sítios arqueológicos supracitados) e as variáveis independentes, que influenciam a localização dos sítios arqueológicos (i.e., Altitude, Declive, Orientação do Declive, Índice de Posição Topográfica, Litologia, Distância ao curso de água mais próximo, Ordem de curso de água mais próximo, Distância à atual linha de costa).

3. Para esta metodologia foram utilizadas 16 Cartas Militares de Portugal à escala 1:25 ooo que abrangem os concelhos de Aljezur, Vila do Bispo, Lagoa, Portimão, Silves e Albufeira. 


\section{RESULTADOS}

\subsection{Análises estatísticas}

As análises estatísticas e exploratórias dos dados permitem estabelecer relações entre os sítios arqueológicos e os atributos de localização, tal como, possíveis padrões intra e inter sítios. Para o presente artigo recorreu-se aos testes estatísticos: Principal Component Analysis (PCA), Hierarchical Cluster Analysis (HCA), Kolmogorov-Smirnov (K-S); e Kruskal-Wallis. De forma a completar a análise recorreu-se à utilização da média, mediana, variância e desvio-padrão, em conjunto com a análise de histogramas e gráficos de frequência acumulada.

O teste PCA permite identificar padrões através da redução do número de dimensões, sem quebras na informação (Smith, 2002). Para esta análise utilizou-se, em primeira instância 8 componentes principais a partir da regra dos engeinvalues superior a 1 . Contudo, deve ser referido que o teste PCA excluiu automaticamente a variável declive, por todas as componentes apresentarem os mesmos valores. Os resultados indicaram que três componentes representam a maior parte da variabilidade dos dados, concretamente explicam $79,59 \%$ da variabilidade da amostra. A primeira componente é responsável por $33,90 \%$ e as restantes por $24,65 \%$ e $21,04 \%$, respetivamente. De forma a estabelecer-se novas relações entre as componentes foram realizadas novas correlações, no entanto os valores obtidos demonstram que o tamanho da amostra influência significativamente os resultados obtidos, não permitindo selecionar as variáveis mais significativas através deste método (Tabela 2 e Figura 3).

Numa fase seguinte foi efetuada uma análise de clusters (HCA) de modo a classificar os sítios arqueológicos em grupos homogéneos, através das similaridades observadas entre eles (Yim \& Ramdeen, 2015). A análise de clusters desenvolvida no âmbito do presente trabalho baseou-se no método de agrupamento hierárquico, através do método de aglomeração Ward e como medida de dissimilitude utilizou-se a distância euclidiana. Os resultados permitem aferir a existência de, possivelmente, três grupos principais: (1) Curva do Beliche, Praia da Galé, Vale Santo e Companheira; (2) Lagoa do Bordoal e Ibn Ammar; (3) Lagoa Funda 1, Lagoa Funda 3, Vale da Fonte, Lagoa Funda 2. $\mathrm{O}$ teste K-S permite determinar a distribuição da variável independente numa determinada amostra, a partir do cálculo da diferença entre a frequência de cada uma das observâncias (e.g., sítios arqueológicos) e a frequência acumulada que essa observação teria se a sua distribuição fosse normal (e.g., os pontos aleatórios) (Gonçalves, 2014). Os resultados da amostra indicam que as variáveis Orientação do declive (OrientDEC), Índice de Posição Topográfica (TPI) e Ordem de Linha de Água (OrdemLA) apresentam uma probabilidade igual ou superior a $5 \% \mathrm{e}$, por esta razão, foram as únicas a serem incluídas no MPA (Tabela 3).

O último teste realizado, Kruskal-Wallis, prova se a amostra em estudo provém da mesma população ou se de populações diferentes, ou se são amostras de populações com a mesma distribuição. Se o nível de significância for inferior a o,05 considera-se hipótese nula (Ho), uma vez que a distribuição da variável dependente não é aleatória em relação à variável independente, assim a dita variável independente deve ser incluída no modelo. Pelo contrário, se as variáveis apresentarem uma significância superior a 0,05 são rejeitadas, já que não influenciaram a variável dependente (Gonçalves, 2014). De acordo com o teste Kruskal-Wallis não foi possível explorar quais as variáveis a incluir no MPA uma vez que os valores obtidos para o nível de significância são todos inferiores a 0,05 (Tabela 4).

\subsection{Criação do Modelo Preditivo Arqueológico}

Importa referir que a modelação preditiva é imprecisa por defeito, e necessita de ser testada e aperfeiçoada para se obter resultados fiáveis. A criação deste MPA foi realizada num contexto de análise preliminar, sendo que o objetivo seria prever a probabilidade de encontrar novos sítios do Paleolítico Médio e verificar a eficácia deste MPA. Para a criação deste modelo foram considerados exclusivamente os resultados do teste K-S, já que os dados do teste Kruskal-Wallis foram inconclusivos. As variáveis independentes que parecem terem influenciado a localização dos sítios são a Orientação do declive (OrientDecl), o Índice de Posição Topográfica (TPI) e a Ordem do curso de água mais próximo (OrdemLA). Assim, a fórmula para criar o MPA (calculado no ArcGIS através da ferramenta Spatial Analyst Tools> Raster Calculator) é demonstrada por:

Potencial de sítios arqueológicos $=f($ OrientDecl + TPI+OrdemLA)

(Figura 4) 


\section{CONCLUSÕES}

As comunidades de Neandertais ter-se-iam adaptado ao meio ambiente envolvente e a partir do mesmo retirar proveito de todos os seus recursos, facto que pode ser comprovado pela variabilidade alimentar (e.g., animais de pequeno e grande porte, recursos marinhos) (Bicho, 2004a, 2004b) e extração de matérias-primas (e.g., Belixe Sul) próximo dos sítios de ar livre (e.g., Curva do Belixe) (Veríssimo, 2004). Através das características dos sítios arqueológicos foi possível agrupá-los em dois grupos distintos: (1) pela proximidade à linha de costa e estuários; (2) e o outro pela proximidade a lagos (Bicho, 2004a, 2004b). Importa referir que somente dois sítios, Ibn Ammar e Companheira, apresentam material arqueológico em número relevante para futuras análises, os restantes apenas facultaram conjuntos de materiais líticos.

Porém, ainda que um dos objetivos do MPA tenha sido completar esta teoria com novos dados e compreender quais as variáveis que influenciaram a localização dos sítios, de forma a estabelecer padrões de povoamento e exploração do território, tal verificou-se impossível pelo reduzido número de sítios arqueológicos e escassez de dados. Ainda assim é possível avançar com as seguintes conclusões e hipóteses:

1. O número de sítios revelou-se insuficiente para compreender quais as variáveis independentes importantes para a sua localização, como o comprova os resultados obtidos pelo teste Kruskal-Wallis que se revelaram inconclusivos;

2. Os sítios de ar livre encontram-se, na sua maioria, localizados no concelho de Vila do Bispo, enquanto as grutas ocupam, apenas o estuário do rio Arade. Teria sido preferível e de certeza mais proveitoso em termos de resultados restringir a área de estudo somente à região de Vila do Bispo e ter em consideração apenas os seis sítios aí localizados;

3. Apesar da dispersão dos sítios arqueológicos pela área de estudo é possível verificar um (suposto) padrão: as sociedades do Paleolítico Médio preferiam zonas planas, junto a afluentes de rios, incindindo na sua maioria na linha de costa, indo estes pressupostos ao encontro dos modelos teóricos estabelecidos para o Barlavento Algarvio (e.g. Bicho, 2004a; Bicho, 2005; Pereira, Haws \& Bicho, 2012).

A tentativa de criar um MPA contribuiu para se compreender que dados deverão ser tidos em consideração para realização de trabalhos futuros do mesmo género, assim como, erros a evitar.

\section{BIBLIOGRAFIA}

BICHO, Nuno Ferreira (2004a) - As comunidades humanas de caçadores-recolectores do Algarve Ocidental Perspetiva ecológica. In TAVARES, António Augusto, TAVARES, Maria José, CARDOSO, João Luís, eds. - Evolução geohistórica do litoral português e fenómenos correlativos: Geologia, História, Arqueologia e Climatologia. Lisboa: Universidade de Lisboa, pp. 359-396.

BICHO, Nuno Ferreira (2004b) - The Middle Paleolithic occupation of Southern Portugal. In CONARD, Nicholas, ed. - Settlement Dynamics of the Middle Paleolithic and Middle Stone Age II. Tübinger: Kerns Verlag, pp. 513-531.

BICHO, Nuno Ferreira (2005) - The extinction of Neanderthals and the emergence of the Upper Paleolothic in Portugal. Promontoria. Faro, 3:3, pp. 173-228.

BICHO, Nuno, CASCALHEIRA, João, MARREIROS, João (2012) - On the (L)edge: the case of Vale Boi rockshelter (Algarve, Southern Portugal)". In BERGSVIK, Knut, SKEATES, Robin, eds. - Caves in Context. Oxford: Oxbow Books, pp. 65-81.

BOCHERENS, Hervé; DRUCKER, Dorothée; MADELAI$\mathrm{NE}$, Stéphane (2014) - Evidence for a (15)N positive excursion in terrestrial foodwebs at the Middle to Upper Palaeolithic transition in southwestern France: Implications for early modern human palaeodiet and palaeoenvironment. Journal of Human Evolution. 69, pp. 31-43.

BRADTMÖLLER, Marcel, PASTOORS, Andreas, WENINGER, Bernhard; WENIGER, Gerd-Christian (2012) - The repeated replacement model e rapid climate change and population dynamics in Late Pleistocene Europe. Quaternary International. Elsevier. 247, pp. 38-49.

CARR, Christopher, ed. (1985) - For Concordance in Archaeological Analysis: Bridging Data Structure, Quantitative Technique and Theory. Kansas City: Westport Publishers.

COSTA, António (2009) - A aplicabilidade dos SIG e das imagens de satélite na identificação de áreas com potencial arqueológico: estações arqueológicas da Idade do Ferro. Porto: Faculdade de Letras da Universidade do Porto.

COWEN, David (1988) - GIS versus CAD versus DBMS: What Are the Differences?. Photogrammetric Engineering and Remote Sensing. 54:11, pp. 1551-1555.

D’ERRICO, Francesco; SÁNCHEZ GOÑI, Maria Fernanda (2003) - Neanderthal extinction and the millennia scale climatic variability of OIS 3. Quaternary Science Reviews. 22: 8-9, pp. 769-788.

DIAS, João Alveirinho (1998) - Aspetos geológicos do Litoral Algarvio. Genovas.10, 113-128. 
EBERT, James. (2000) - The state of the art in inductive predictive modeling: seven big mistakes (and lots of smaller ones). In WESTCOTT Konnie; BRANDON Joe, eds. Practical Applications of GIS for Archaeologists: A Predictive Modeling Kit. London: Taylor \& Francis, pp. 129-134.

ESRI Portugal (2020) - ArcGis for Desktop. Acedido em junho 12, 2020. In http://www.esriportugal.pt/ArcGIS-for-Desktop.

FABRE, Virginie; CONDEMI, Silvana; DEGIOANNI, Anna; HERRSCHER, Estelle (2011) - Neanderthals versus Modern Humans: Evidence for Resource Competition from Isotopic Modelling. International Journal of Evolutionary Biology. 2011, pp. 1-16. doi:10.4061/2011/689315

GONÇALVES, Célia (2009) - Modelos Preditivos em SIG na localização de sítios arqueológicos de cronologia mesolítica no Vale do Tejo. Algarve: Universidade do Algarve.

GONÇALVES, Célia (2014) - Modelos preditivos de ocupação no território no Mesolítico entre os Vales do Tejo e do Sado. Algarve: Universidade do Algarve.

JUDGE, W. James; SEBASTIAN, Lynne (1988) - Quantifying the Present and Predicting the Past: theory, method and application of archaeological predictive modelling. Denver: U.S. Department of the Interior (Bureau of Land Management Service Center).

KOHLER, Timothy; PARKER, Sandra (1986) - Predictive models for archaeological resource location. In SCHIFFER Michael, ed. - Advances in Archaeological Method and Theory. New York: Academic Press. 1: 9, pp. 397-452.

KVAMME, Kenneth (1990) - The Fundamental Principles and Practice of Predictive Archaeological Modeling. In VOORRIPS, Albertus, ed. - Mathematics and Information Science in Archaeology: A Flexible Framework. Bonn: Holos -Verlag, pp. 257-295.

MAIO, Daniela (2018) - Ocupação Paleolítica no Barlavento Algarvio: Modelos Preditivos Com Recurso aos SIG. Algarve: Universidade do Algarve.

MENDONÇA, Carolina. (2009) - A tecnologia lítica no tardiglaciar no Algarve. Algarve: Universidade do Algarve

MOURA, Delminda. e Boski, Tomasz. (1999) - Unidades litostratigráficas do Pliocénico e Plistocénico no Algarve. Comunicações do Instituto Geológico e Mineiro.86, pp. 85-106.

NAZARENO, Nilton (2005) - SIG arqueologia: aplicação em pesquisa arqueológica. Brazil: Universidade de São Paulo.

PAIXÃO, Eduardo; CANINAS, João; CARVALHO, Emanuel; FIGUEIREDO, Olívia; HENRIQUES, Fernando; MAIO, Daniela; MENDES, Cátia; NORA, David; PEREIRA, André; PEREIRA, Telmo; RAPOSO, Luís (2016) - A Jazida Moustierense de Cobrinhos, Vila Velha de Ródão (Portugal). Actas II Internacional conference of archeology of Castelo Branco region. Portugal: Castelo Branco. pp. 131-146.

PEREIRA, Telmo; BENEDETTI, Michael (2013) - A model for raw material management as a response to local and glo- bal environmental constraints. Elsevier: Quaternary International. Série XXX, pp. 1-14.

PEREIRA, Telmo; HAWS, Jonathan; BICHO, Nuno (2012) - O Paleolítico Médio no Território Português. Mainake. Série XXXIII, pp. 11-30.

PROJECT Development (2005) - The Archaeological Predictive Model: Revised Archaeological Predictive Model. Project Development 64.United States.

RAPOSO, Luís (1995) - Ambientes, territórios y subsistência en el Paleolítico Médio de Portugal. Complutum. 6, pp. 57-7.

SMITH, Lindsay (2002) - A tutorial on Principal Components Analysis. Computer Science Technical Report. Nova Zealandia: Departamento das Ciencias Computacionais da Universidade de Otago. Série OUCS-2002-12, pp. 1-26.

STRINGER, Chris (2002) - New Perspectives on the Neanderthals. Evolutionary Anthropology. Suppl 1, pp. 58-59. DOI 10.1002/evan.10057

VERHAGEN, Philip (2018) - Spatial Analysis in Archaeology: Moving into New Territories. In SIART Christoph; FORBRIGER, Markus; BUBENZER Olaf, eds. - Digital Geoarchaeology: Natural Science in Archaeology. Springer. Cham.

VERÍSSIMO, Hugo (2004) - Jazidas siliciosas da região de Vila do Bispo (Algarve). Promontoria. 2: 2, pp. 35-47.

WARREN, Robert (1990) - Predictive modeling of archaeological site location: a primer. In ALLEN, Kathleen; GREEN, Stanton; ZUBROW, Ezra, eds. - Interpreting Space: GIS and Archaeology. London: Taylor \& Francis, pp. 8o-111.

WARREN, Robert; ASHCH, David (200o) - A Predictive Model of Archaeological Site Location in the Eastern Prairie Peninsula. In WESCOTT K, BRANDON R., eds. - Practical Applications of GIS for Archaeologists: A Predictive Modeling Kit. London: Taylor \& Fisher, pp. 5-25.

WIßING, Christoph; ROUGIER, Hélène; BAUMANN, Chris; COMEYNE, Alexander; CREVECOEUR, Isabelle; DRUCKER, Dorothée; GAUDZINSKI-WINDHEUSER, Sabine; GERMONPRÉ, Mietje; GÓMEZ-OLIVENCIA, Asier; KRAUSE, Johannes; MATTHIES, Tim; NAITO, Yuichi; POSTH, Cosimo ; SEMAL, Patrick; STREET, Martin; BOCHERENS Hervé (2019) - Stable isotopes reveal patterns of diet and mobility in the last Neandertals and first modern humans in Europe. Scientific Reports. 9: 4433, pp. 2-12. https://doi.org/10.1038/s41598-019-41033-3

YIM, Odilia; RAMDEEN, Kylee (2015) - Hierarchical Cluster Analysis: Comparison of Three Linkage Measures and Application to Psychological Data. The Quantitative Methods for Psychology. 11:1, pp. 8-21.

ZILHÃO, João (2014) - The Neanderthals: Evolution, Palaeoecology, and Extinction. In CUMMINGS, Vicki; JORDAN, Peter; ZVELEBIL, Marek, eds. - The Oxford Handbook of the Archaeology and Anthropology of Hunter-Gatherers. Oxford: Oxford University Press, pp. 191-213. 

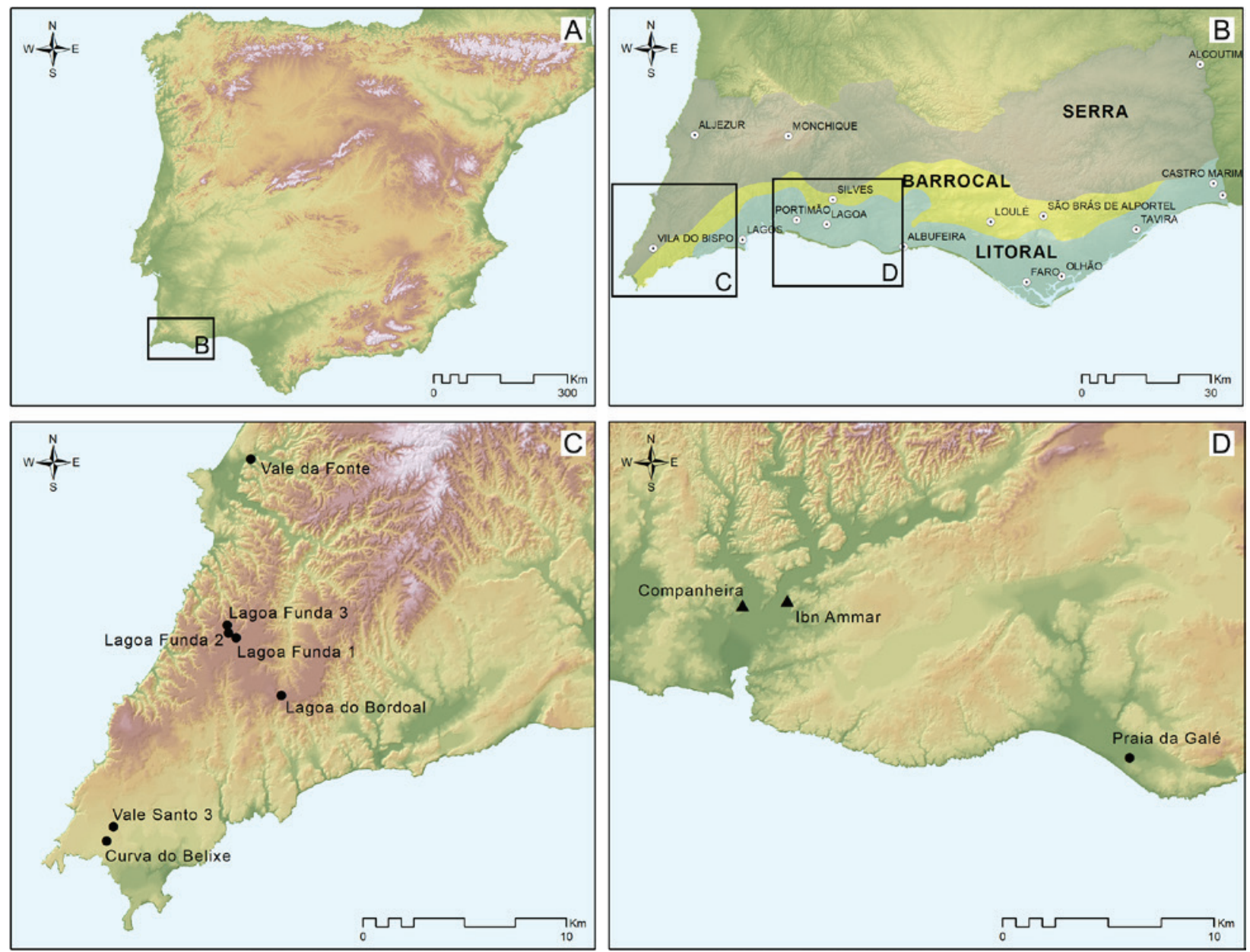

Figura 1 - Mapa da localização dos sítios arqueológicos do Paleolítico Médio no Barlavento algarvio. Legenda das Figura C e D: círculo - sítio de ar livre; triângulo - gruta.

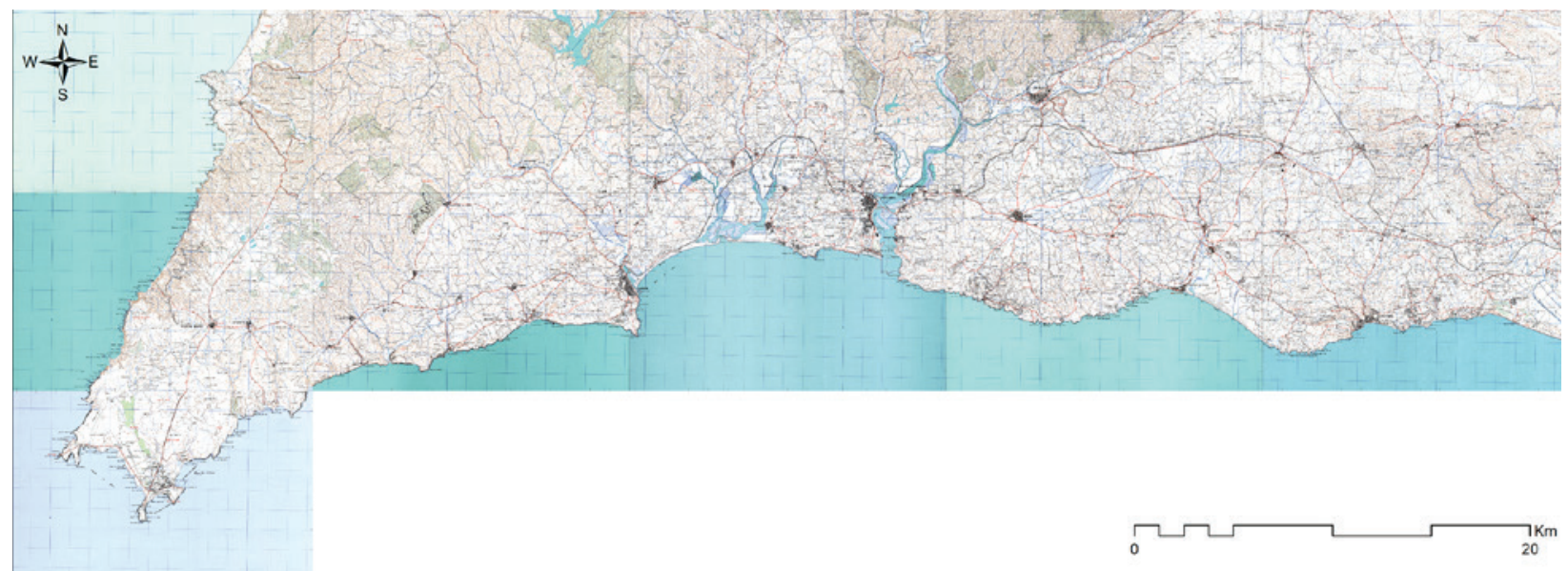

Figura 2 - Mapa das Cartas Militares Portuguesas (folhas no 583a, 584,585, 586,587, 592, 593, 594, 595, 596, 601, 602, 603, 6o, 605 e 6o9) da área de estudo (Barlavento algarvio). 


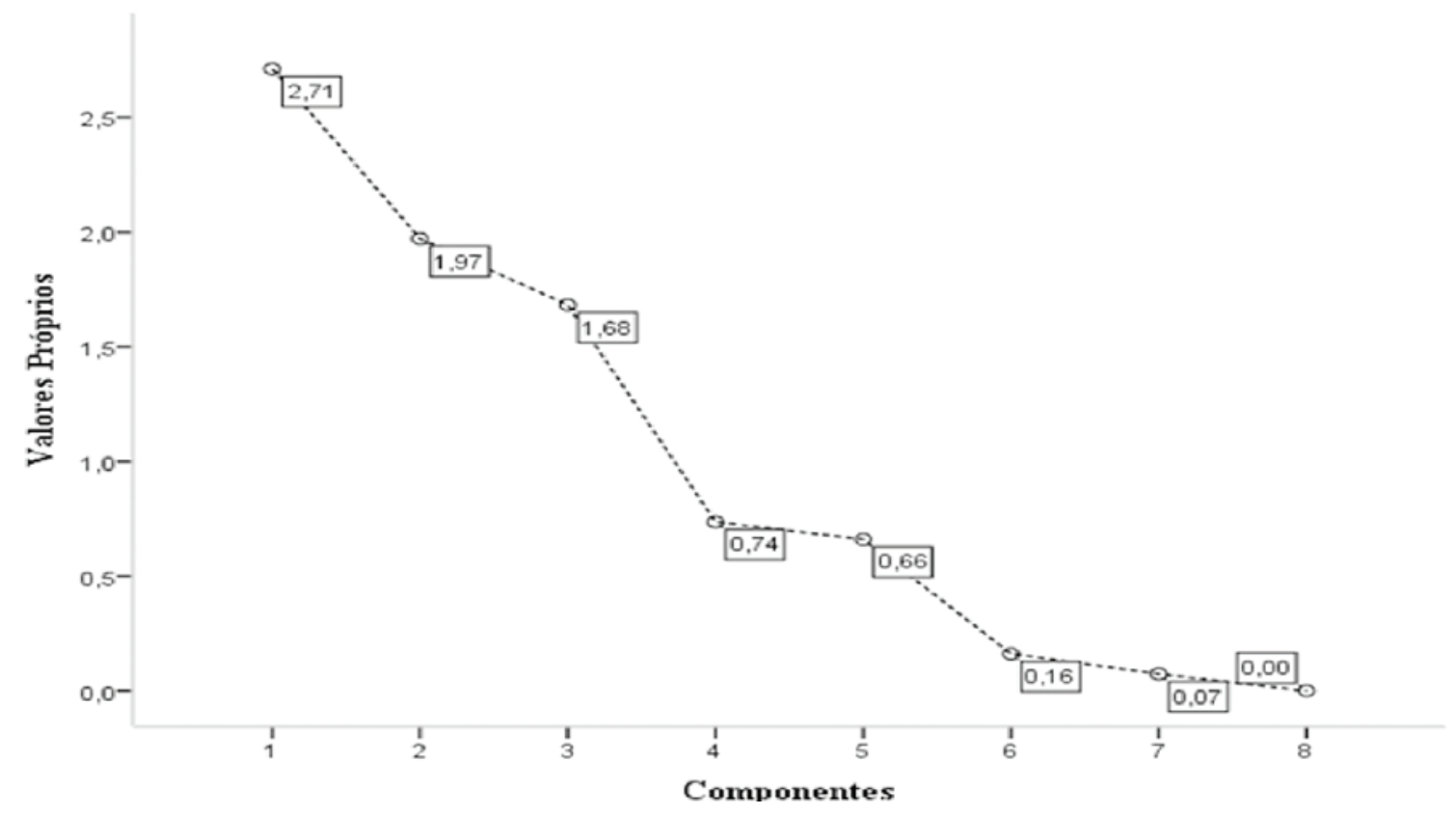

Figura 3-Gráfico scree plot dos engeinvalues e os valores decrescentes da variância explicada do teste PCA sobre as variáveis independentes, da área de estudo.

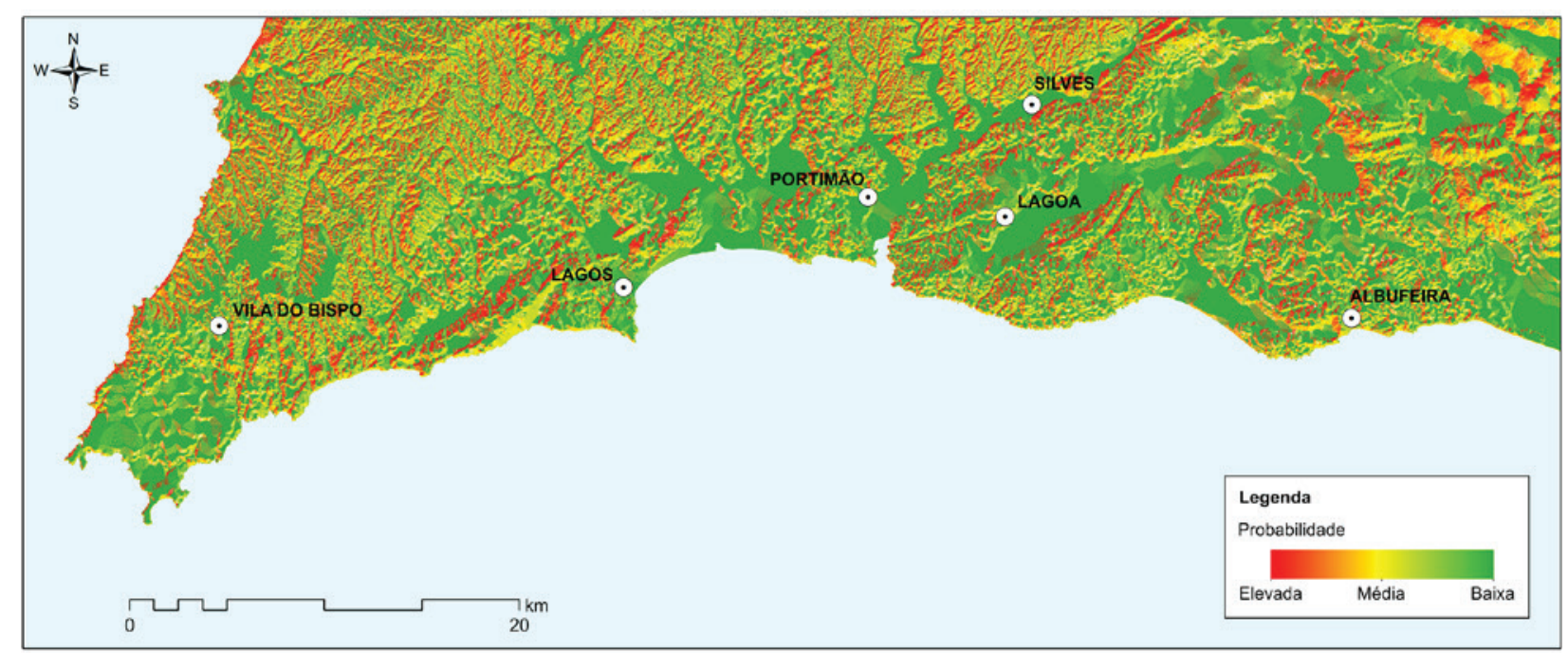

Figura 4 - Mapa de probabilidade de existência de sítios arqueológicos do Paleolítico Médio, na área de estudo, segundo os resultados do teste K-S. 


\begin{tabular}{|c|c|c|c|c|c|c|c|c|c|}
\hline $\begin{array}{c}\text { Sítio } \\
\text { arqueológico }\end{array}$ & $\begin{array}{l}\text { Altitude } \\
\text { (m) }\end{array}$ & $\begin{array}{l}\text { DistLA } \\
(\mathrm{m})\end{array}$ & OrdemLA & NomeLA & $\begin{array}{l}\text { DistLC } \\
(\mathrm{m})\end{array}$ & Declive $^{1}$ & OrientDEC & $\mathrm{TPI}^{2}$ & Litologia $^{3}$ \\
\hline Praia da Galé & 10 & 900 & 4 & $\begin{array}{c}\text { Braço do } \\
\text { Vale } \\
\text { da Vila }\end{array}$ & 670 & 1 & -1 & 3 & 7 \\
\hline Curva do Belixe & 54 & 876 & 3 & - & 770 & 1 & -1 & 3 & 6 \\
\hline Vale Santo 3 & 60 & 310 & 3 & - & 1500 & 1 & -1 & 3 & 9 \\
\hline Lagoa Funda 1 & 130 & 981 & 4 & $\begin{array}{c}\text { Ribeiro } \\
\text { do Baralho }\end{array}$ & 2762 & 1 & -1 & 3 & 7 \\
\hline Lagoa Funda 2 & 130 & 1356 & 3 & - & 3236 & 1 & -1 & 3 & 7 \\
\hline Lagoa Funda 3 & 120 & 628 & 3 & - & 2558 & 1 & -1 & 3 & 4 \\
\hline Lagoa do Bordoal & 130 & 1068 & 3 & - & 4379 & 1 & -1 & 3 & 6 \\
\hline Vale da Fonte & 20 & 47 & 3 & - & 2649 & 1 & -1 & 3 & 11 \\
\hline Ibn Ammar & 10 & 350 & 5 & Rio Arade & 5014 & 1 & -1 & 3 & 2 \\
\hline Companheira & 10 & 28 & 3 & Rio Arade & 1215 & 1 & 135 & 4 & 7 \\
\hline
\end{tabular}

Tabela 1 - Atributos dos sítios arqueológicos do Paleolítico Médio. Legenda: Declive: 1 - Muito suave a plano, 2 - Suave, 3 Acentuado, 4-Muito acentuado. TPI: 1 - Vales, 2 - Vertente curta, 3-Planicie, 4-Vertente Média, 5-Vertente longa, 6 - Crista. Litologia: 1 - aluviões; 2 - xistos argilosos, grauvaques; 3 - doleritos; 4 - grés vermelhos (de silves), conglomerados, margas; 5 - arenitos, conglomerados, calcários margosos; 6 - calcários, calcários dolmíticos, calcários margosos; 7 - areias, calhaus rolados, arenitos pouco consolidados; 8 - conglomerados, arenitos, calcários; 9 - areias e cascalheiras; 10 - arenitos, calcários mais ou menos consolidados; 11 - estuários (margens dos rios); 12 - dunas e areias eólicas; 13 - basaltos.

\begin{tabular}{lccc} 
& & & \\
\cline { 2 - 4 } & $\mathbf{1}$ & \multicolumn{1}{c}{ COMPONENTE } & \\
\cline { 2 - 4 } Altitude & $-0,76$ & 0,404 & $-0,118$ \\
\hline Declive & 0.00 & 0.00 & 0.00 \\
\hline OrientDEC & $-0,442$ & $-0,053$ & $-0,008$ \\
\hline TPI & $-0,063$ & $-0,316$ & $-0,081$ \\
\hline Litologia & 0,169 & 0,050 & $-0,405$ \\
\hline DistLA & 0,103 & 0,441 & $-0,035$ \\
\hline OrdemLA & 0,109 & $-0,104$ & 0,478 \\
\hline DistLC & 0,032 & 0,118 & 0,336 \\
\hline
\end{tabular}

Tabela 2 - Tabela do teste PCA. Análise das componentes principais e o peso de cada variável independente nas três componentes principais, sobre a área de estudo. 


\begin{tabular}{lccc} 
& DMAX & NÍVEL DE SIGNIFICÂNCIA & PROBABILIDADE \\
\hline Altitude & 0,257 & 0,00 & $0 \%$ \\
\hline Declive & 0,000 & 0,00 & $0 \%$ \\
\hline OrientDEC & 0,524 & 0,05 & $5 \%$ \\
\hline TPI & 0,524 & 0,05 & $5 \%$ \\
\hline Litologia & 0,235 & 0,00 & $0 \%$ \\
\hline DistLA & 0,187 & 0,00 & $0 \%$ \\
\hline OrdemLA & 0,416 & 0,10 & $10 \%$ \\
\hline DistLC & 0,146 & 0,00 & $0 \%$ \\
\hline
\end{tabular}

Tabela 3 - Tabela do teste Kolmogorov-Smirnov. Resultados do teste Kolmogorov-Smirnov sobre as variáveis independentes referentes aos sítios do Paleolítico Médio, na área do barlavento algarvio. Sendo que, Dmax> 0,405 o nível de significância é <0,1 (menos de 10\% de probabilidade da diferença ser insignificante; Dmax > 0,451 o nível de significância é <0,05 (menos de 5\% de probabilidade da diferença ser insignificante); Dmax> 0,540 o nível de significância é <0,o1 (menos de 1\% de probabilidade da diferença ser insignificante).

\begin{tabular}{lcc}
\cline { 2 - 3 } & QUI-QUADRADO & NÍVEL DE SIGNIFICÂNCIA \\
\hline Altitude & 8,220 & 0,314 \\
\hline OrientDEC & 4,000 & 0,406 \\
\hline Litologia & 2,129 & 0,546 \\
\hline Declive & 0,000 & 1,000 \\
\hline TPI & 4,000 & 0,261 \\
\hline distLA & 9,000 & 0,437 \\
\hline OrdemLA & 2,250 & 0,325 \\
\hline DistLC & 2,000 & 0,368 \\
\hline
\end{tabular}

Tabela 4 - Tabela do teste Kruskal-Wallis. Resultados do teste Kruskal-Wallis para seleção das variáveis independentes, na área do barlavento algarvio. 


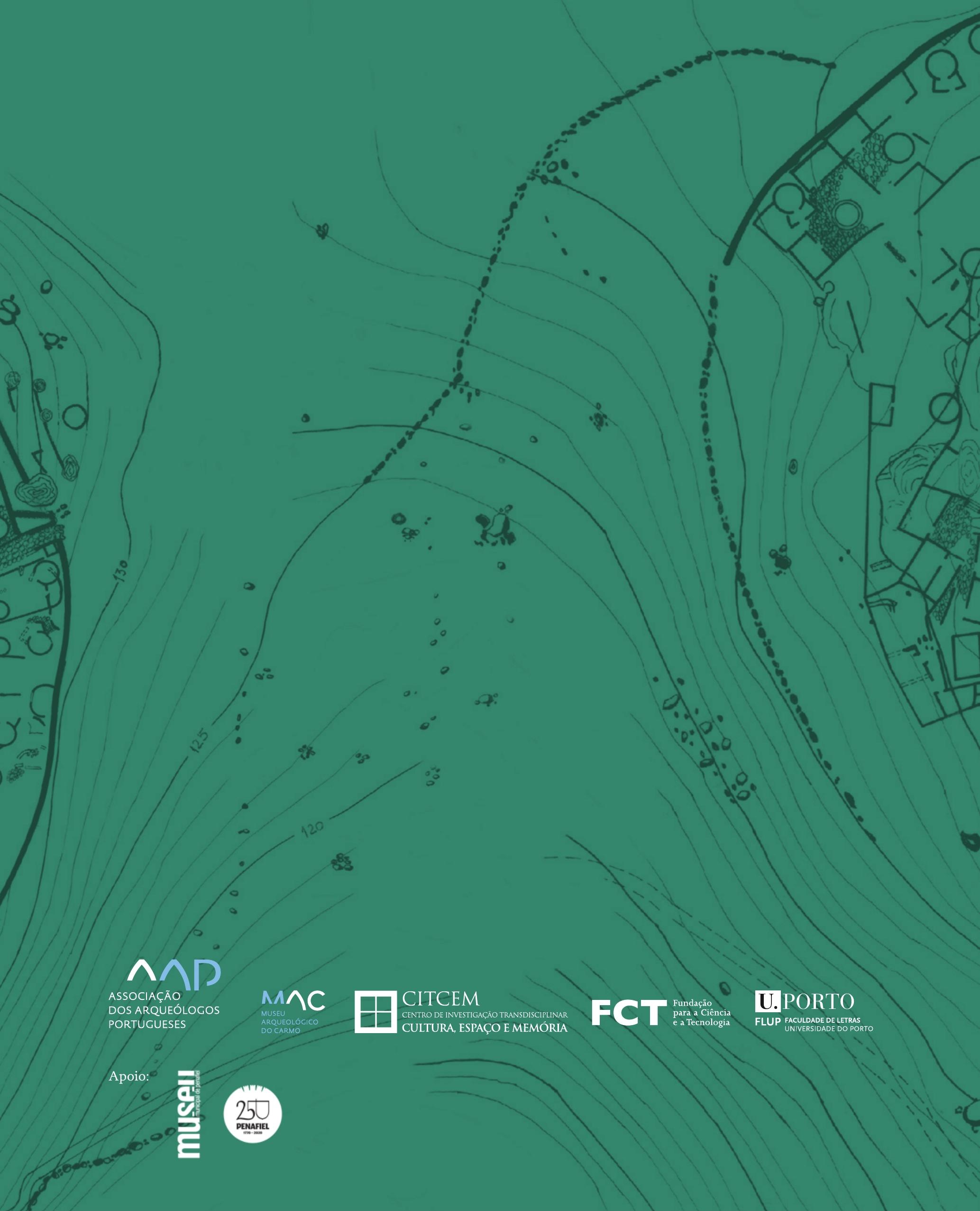

